\title{
THE PATCHWORK TEXT AS ASSESSMENT TOOL FOR POSTGRADUATE LAW TEACHING IN SOUTH AFRICA
}

\author{
JG Horn \\ B Proc LLB LLM MA (HES) LLD \\ Senior Lecturer, Department of Private Law, \\ University of the Free State \\ L van Niekerk \\ LLB LLM PGD in Financial Planning Law MA \\ (HES) \\ Lecturer, Department of Mercantile Law, \\ University of the Free State
}

SUMMARY

In the increasingly competitive higher education sphere, delivering graduates with a sound academic grounding in their discipline is no longer enough. Institutions of higher learning must yield lifelong learners who are employable and equipped with the practical skills required by the profession. To ensure this, the right assessment approach is key. While assessment has always been a crucial component of instruction, traditional assessment tools run the risk of being mere tools for certification, facilitating surface learning instead of deep learning. Assessment approaches need to be re-evaluated to strike a balance between encouraging deep learning and instilling proper academic knowledge in graduates. To contribute to such a re-evaluation of traditional assessment methods, this article reports on the introduction of the patchwork text (PWT) as an alternative assessment tool in postgraduate law teaching at the University of the Free State (UFS). After making the case for the move towards more authentic, alternative assessment techniques, the authors embark on a discussion of the main features of the PWT, as well as guidelines for drafting a PWT assessment. The focus then shifts to an overview of PWT implementation in other postgraduate modules, ending with a discussion of the authors' experience introducing the PWT in their own teaching. Useful information about the authors' approach is shared, including examples of formative assessment exercises used as part of the PWT, specifics regarding the portfolio of evidence of learning to be handed in, and an outline of the four "patches" making up the assessment. It is concluded that the PWT has proven to be a viable tool for assessing postgraduate students in certain law modules at the UFS. It has managed to promote deep learning, develop students into critical thinkers and problem-solvers, and compel them to continuously engage with the study material - all while achieving the intended learning outcomes. The PWT is therefore recommended to lecturers who seek to equip students with a macro-vision of their field of study, the ability to 
integrate and contextualise different areas of the discipline, and the skill to reflect critically on new, emerging developments in the field.

\section{$1 \quad$ INTRODUCTION}

Competition in higher education is fierce. Institutions of higher learning first vie for the best students, and then compete to deliver graduates of the best quality. Law faculties in particular are required to yield graduates with not only a sound academic grounding, but also the practical experience expected by the profession.

To ensure that graduates have the desired knowledge as well as the practical skills to add value to the workplace, the right assessment approach is key. Indeed, assessment has always been a crucial component of instruction. ${ }^{1}$ However, considering the new, modern-day demands on higher education and on the graduates it delivers, traditional assessment methods run the risk of being mere tools for certification, instead of equipping students as lifelong learners ready for the workplace. ${ }^{2}$ Therefore, there is a need to re-evaluate assessment approaches and take positive action.

Using an appropriate assessment method may encourage students to engage continuously with the study material, which may lead to a deeper level of understanding and a firmer grasp of module content. That would satisfy the ultimate aim of higher education - namely, to enable deep learning instead of mere surface learning. ${ }^{3}$ Constant reflection on assessment strategies in the higher education sphere is vital to determine whether current practices encourage only superficial learning and, if so, what changes should be introduced. This implies that, in selecting and designing assessment tools, faculties need to strike a balance between encouraging deep learning and instilling proper academic knowledge in graduates.

As lecturers in two postgraduate coursework law modules at the University of the Free State (UFS), South Africa, the authors too became acutely aware of the need to explore and pursue more effective assessment practices to achieve the tricky balance stated above. As their contribution in this regard, this article evaluates the feasibility of the patchwork text (PWT) as an alternative assessment tool, as implemented in the authors' respective modules. The primary objective is to identify whether the PWT is a viable tool to compel students in postgraduate law modules to engage continuously with the study material. A secondary objective is to determine whether the PWT succeeds in achieving the intended learning outcomes of the modules.

For purposes of this article, the PWT is seen as an alternative assessment tool made up of a number of challenging tasks ("patches") linked to real-life situations, which are shared with peers in a critical manner. Patches are selected in consultation with peers and are presented in an

Dikli "Assessment at a Distance: Traditional vs. Alternative Assessment" 20032 Turkish Online Journal of Educational Technology 1313.

2 Bourner "The Broadening of the Higher Education Curriculum" 200436 Higher Education Review 3946

3 Biggs Teaching For Quality Learning at University 2ed (2003) 14-18. 
abridged portfolio, in which they are "stitched together" through final reflection, and learning is consolidated. ${ }^{4}$ The PWT develops important generic skills, such as a macro-vision of the field of study, critical thinking skills, technology skills and teamwork through peer discussion. A more detailed discussion of the PWT follows under heading 4.

\section{THE CHOICE OF ACTION RESEARCH}

Being integrally involved in the process of implementing the PWT, and driven by the need to critically evaluate the success of this assessment tool, the authors opted for the action research approach as the most appropriate methodology.

Action research pursues both action and research simultaneously. ${ }^{5}$ It is defined as:

"[a] form of collective self-reflective enquiry undertaken by participants in social situations in order to improve .... their own social or educational practices, as well as their understanding of these practices and the situations

in which the practices are carried out."

This type of research is participatory (with researchers contributing equally) and collaborative (with researchers partnering with and for those affected by the "problem"), and typically arises from the clarification of concerns generally shared by a group.

The action research approach involves (i) identifying the problem, (ii) action planning, (iii) implementation of the action plan, (iv) evaluation and, finally, (v) reflection. ${ }^{8}$ For this article, the authors identified the problem, being a need for change in assessment methods to deliver law graduates who are both immediately employable and committed to lifelong learning. The researchers then planned the assessments to be used in two postgraduate law modules, implemented the assessments, observed their effects, and critically reflected on the findings so as to improve the assessment tool and current practices. The authors acted as critical change agents, conducting evaluative research in pursuit of ways to change both their practice and themselves for the better. The accountability of this methodology lies in the publication of the learning process and its results.

Some benefits of action research include that it solves a practical problem systematically and collaboratively. It improves the practice of learning,

4 Winter "Contextualising the Patchwork Text: Addressing Problems of Coursework Assessment in Higher Education" 200340 Innovations in Education and Teaching International 112112.

5 Dick, as cited in Altrichter, Kemmis, McTaggart and Zuber-Skerritt "The Concept of Action Research" 20029 The Learning Organization 125131.

Kemmis and McTaggart The Action Research Reader (1988) 5.

Altrichter et al 2002 The Learning Organization 131.

Ibid. 
teaching, training, management and professional development, as well as the social context and conditions in which this practice takes place. ${ }^{9}$

This research method was previously used in a similar study to evaluate the implementation of the patchwork text, albeit in a different discipline. The researchers in that study found that implementation of the patchwork text as an assessment tool had to be monitored through the deliberate use of an action research plan to result in improvement and quality assurance. ${ }^{10}$ This served as further motivation for the authors' choice of action research for this study.

\section{WHY THE MOVE TOWARDS ALTERNATIVE ASSESSMENT?}

Traditionally, assessment was seen mainly as a tool to determine whether a student may proceed to the next level. However, since the 1990s, the need to prepare students as lifelong learners has become more prominent, with assessment no longer regarded as a mere tool for certification. ${ }^{11}$ Assessment is central to the student learning experience, ${ }^{12}$ and assessment tools are said to be among the greatest influences on how and what students learn. ${ }^{13}$ Poor assessment practices are often the reason for lowquality instruction and learning. ${ }^{14}$

As such, student assessment first needs to be appreciated for its role in student learning and, secondly, must be carefully planned to achieve the desired outcomes.

\section{Assessment shapes learning}

One might think that learning is shaped by module outcomes or structure. Yet, learning is in fact shaped by assessment. If lecturers wish to change the way students learn, they must change the way students are assessed. ${ }^{15}$ Assessment should not be used as a mere tool to test students, but should form part of the learning process itself. ${ }^{16}$

9 Zuber-Skerritt "Participatory Action Learning and Action Research (PALAR) for Community Engagement: A Theoretical Framework" 20154 Educational Research for Social Change 5 17-18.

10 Van Tonder, Wilkinson and Van Schoor "Patchwork Text: Innovative Assessment to Address the Diverse Needs of Postgraduate Learners at the African University of the $21^{\text {st }}$ Century" 200519 SAJHE 1282 1302-1303.

11 Bourner 2004 Higher Education Review 46.

12 Brown and Knight in Upton and Taylor "Is Online Patchwork Text Assessment a Panacea for Assessment Practices in Higher Education?" 201319 Psychology Teaching Review 44 44.

13 Hong Kong Baptist University "Assessment of Student Learning" (1998) http://www.hkbu.edu.hk/ ar/staff/qa/tlqprii.htm (accessed 2004-06-25).

14 Dochy and McDowell "Assessment as a Tool for Learning" 199723 Studies in Educational Evaluation 279286

15 Brown "Assessment: A Guide for Lecturers" (2001) http://www.Itsn.ac.uk (accessed 201811-02).

16 Trevelyan and Wilson "Using Patchwork Texts in Assessment: Clarifying and Categorizing Choices in Their Use" 201237 Assessment and Evaluation in Higher Education 487488. 
Assessment enables the lecturer to understand the processes and outcomes of student learning, and to determine the quality of learning that has taken place. ${ }^{17}$ The choice of assessment method will encourage different approaches to learning. ${ }^{18}$ It follows, then, that lecturers seeking to foster deep learning in their students should choose an assessment tool to achieve that.

For purposes of this article, assessment tools are defined as those instruments, including tests and assignments, used as part of the structured process of gathering evidence and making judgements about an individual's performance against registered national standards. ${ }^{19}$ The selection of an assessment tool when designing a module is integral to the module's success, as it acts as an intervention in student learning, ${ }^{20}$ developing skills and competencies that students will need beyond the course. The chosen assessment must also develop important generic skills, such as the ability to have a macro-view of the field of study, and the skill to collaborate with peers as part of a team. When a degree is awarded, this should signify that the graduate has largely achieved the outcomes of the curriculum, and that what has been achieved is transferable not only to the workplace, but to other spheres of life as well. ${ }^{21}$ The testing of core knowledge and skills must be geared towards this purpose, and the threshold between fail and pass must be very distinct. ${ }^{22}$ Upon graduation, undergraduate law students, for instance, must have developed generic skills and applied competencies such as critical thinking skills, research skills, communication and literacy skills, problem-solving skills and the transfer of acquired knowledge. Critical thinking skills should include legal reasoning, critical analysis and creative thinking. ${ }^{24}$

A valid and credible assessment tool should therefore include appropriate tasks for testing the desired skills. In addition, it must assess what it initially set out to assess, and not what is merely easy to assess. ${ }^{25}$ According to Geyser, ${ }^{26}$ such credibility of assessment can be attained if:

- the assessment is an integral part of learning (focusing on deep, active learning and involving high-order cognitive skills), of programme and module design, and of quality assurance procedures;

17 Hong Kong Baptist University http://www.hkbu.edu.hk/ ar/staff/qa/tlqprii.htm.

18 Ibid.

19 Dikli 2003 Turkish Online Journal of Educational Technology 14; SAQA Criteria and Guidelines for Assessment of NQF Registered Unit Standards and Qualifications (2001) 16.

20 Bearman, Dawson, Boud, Bennet, Hall and Molloy "Support for Assessment Practice: Developing the Assessment Design Decisions Framework" 201621 Teaching in Higher Education 545547.

21 Knight "Summative Assessment in Higher Education: Practices in Disarray" 200227 Studies in Higher Education 275276.

22 Brown http://www.Itsn.ac.uk.

23 CHE Qualification Standard for Bachelor of Laws (LLB) (2015) 9.

24 Burton "Teaching and Assessing Problem Solving: An Example of an Incremental Approach to Using IRAC in Legal Education” 201613 Journal of University Teaching and Learning Practice 11.

25 Joubert "Paradigm Shift in Assessment Methodology for Law Students in South Africa" 2013 10 Journal of College Teaching and Learning 5556.

26 Geyser "Learning From Assessment" in Gravett and Geyser (eds) Teaching and Learning in Higher Education (2004) 92. 
- the assessment purpose determines the assessment methods and techniques;

- the assessment criteria are clearly identified and applied;

- the assessment processes are reliable;

- the assessment tasks are valid and practicable;

- the assessment is transparent and fair;

- the assessment workload is realistic;

- the assessment includes a wide range of approaches and methods; and

- the assessor provides feedback to support the learning process.

Consequently, in light of the key role of assessment in fostering deep learning and true engagement with learning material, the importance of selecting the most appropriate assessment tool cannot be overstated.

\section{Drawbacks of traditional assessment}

With traditional assessment methods, students focus only on the topic being assessed, while other areas of learning fade away, ${ }^{27}$ resulting in mere surface learning. This type of higher education assessment may be described as assessment of learning, whereas the focus of alternative assessment is on assessment for learning. ${ }^{28}$

For the most part, the UFS Faculty of Law still applies the traditional assessment method at postgraduate level. Lecturers set assignments in the form of essay questions, which are then scored to produce a semester or year mark, while a closed-book examination containing similar essay-type questions is used as summative assessment. ${ }^{29}$

Generally, the focus is more on summative assessment, with little to no attention being paid to formative assessment. Summative assessment is used to evaluate students during the module, and contributes towards their final mark. Formative assessment, on the other hand, is used not to evaluate students, but to afford them an opportunity to ascertain for themselves, often based on lecturer feedback, their progress towards achieving the intended module outcomes. ${ }^{30}$ An overemphasis on summative assessment is said to be the breeding ground for surface learning. ${ }^{31}$

One of the drawbacks of traditional assessment is the lack of feedback from the lecturer or the person assessing the work. ${ }^{32}$ When done properly,

27 Wesson "Introducing Patchwork Assessment to a Social Psychology Module: The Utility of Feedback" 201319 Psychology Teaching Review 9797.

28 Williams "Squaring the Circle: A New Alternative to Alternative-Assessment" 201419 Teaching in Higher Education 565566.

29 UFS General Rules for Undergraduate Qualifications, Postgraduate Diplomas, Bachelor Honours Degrees, Master's Degrees, Doctoral Degrees, Higher Doctorates, Honorary Degrees and the Convocation https://www.ufs.ac.za/docs/default-source/alldocuments/2018a-general-rules-final-version-7-for-publication-2---24-january-2018--final_ese80ccae65b146fc79f4fff0600aa9400.pdf?sfvrsn=4418a521_0 7 (accessed 2020-0305).

Geyser Teaching and Learning in Higher Education 92.

31 Knight 2002 Studies in Higher Education 278.

32 Williams 2014 Teaching in Higher Education 566. 
feedback should motivate students and guide them on how well they have done and how they can improve further. ${ }^{33}$ Instead of providing only brief, after-the-fact feedback when the learning cycle has already been completed, ${ }^{34}$ feedback should be "timely, perceived as relevant, meaningful, encouraging and offer suggestions for improvement that are within a students' grasp". ${ }^{35}$ When a lecturer provides constructive feedback, it has been shown to have a high motivational value that enhances a student's learning and improves the learning process. ${ }^{36}$

Another drawback of traditional assessment is that students graduate without having mastered the skills really required in the workplace. There is growing concern about the discrepancy between graduates' skills and competencies, and the requirements of future employers. In the law curriculum specifically, the focus of assessment should be on problemsolving and accomplishing tasks as experienced in the profession. ${ }^{37}$ The general outcomes prescribed by the faculty for successfully completing a postgraduate degree entails higher order learning by placing a major emphasis on high-level theoretical-intellectual engagement that can be applied in legal practice. Furthermore, students need to master the ability to select and employ methods and techniques to apply to complex practical and theoretical problems in law. ${ }^{38}$

Many higher education stakeholders struggle with the question of what skills should be imparted to turn students into lifelong learners and enable them to compete effectively in the workforce. ${ }^{39}$ In some instances, even students transitioning from undergraduate to postgraduate studies lack the skills and competencies prescribed by the South African Qualifications Authority (SAQA). Therefore, it is essential for assessment at both undergraduate and postgraduate level to be designed so as to develop these desired skills and competencies in graduates. Such assessment needs to be authentic and to focus on real-life experiences. ${ }^{40}$ The assessment criteria must be transparent and simple, fair and reliable, and must align with the outcomes initially set. ${ }^{41}$

33 Brown http://www.Itsn.ac.uk.

Williams 2014 Teaching in Higher Education 567.

Brown http://www.Itsn.ac.uk.

36 Williams 2014 Teaching in Higher Education 567; Biggs Teaching for Quality Learning at University 141.

37 Burton 2016 Journal of University Teaching and Learning Practice 1.

38 UFS Faculty of Law Postgraduate Degrees and Diplomas (2018) https://apps.ufs.ac.za/dl/yearbooks/311_yearbook_eng.pdf 23-24 (accessed 2020-03-05).

39 Volkov and Volkov "Teamwork Benefits in Tertiary Education: Student Perceptions That Lead to Best Practice Assessment Design" 201557 Education and Training 262263.

40 McMillan Classroom Assessment: Principles and Practice for Effective Instruction (2004) $14-17$.

41 University of Sheffield "Principles of Assessment" (undated) https://www.sheffield.ac.uk/polopoly_fs/1.209653!file/Principles_of_Assessment.pdf (accessed 2018-12-13); McMillan Classroom Assessment: Principles and Practice for Effective Instruction 99-101. 


\section{The need for more authentic, alternative assessment}

It is this need for a more authentic assessment method, which fosters real understanding and results in a deeper level of learning, that compelled the authors to investigate alternative assessment tools for use in their own postgraduate modules.

The terms "authentic" and "alternative" assessment are used interchangeably. Authentic (and, thus, alternative) assessment is defined as follows:

"[M]ethods of assessment which influence teaching and learning positively in ways which contribute to realizing educational objectives, requiring realistic (or 'authentic') tasks to be performed and focusing on relevant content and skills, essentially similar to the tasks involved in the regular learning processes in the classroom."

The aim of alternative assessment is "to relate the instruction to the realworld experiences of learners". ${ }^{43}$ Alternative assessment tools help students become more actively engaged and take ownership of their learning by reflecting their knowledge of course material "in their own ways by using various intelligences". ${ }^{44}$ Assisting students to become autonomous learners, ${ }^{45}$ alternative assessment focuses on the student's growth and performance, ${ }^{46}$ and requires "higher-order thinking skills so that students can solve real-life related problems". ${ }^{47}$

Aside from the PWT, Winter ${ }^{48}$ identifies another two alternative assessment tools - namely, the coursework essay and the portfolio.

The coursework essay is a popular form of assessment to teach students scientific writing skills. The essay can be easily distributed and administered, and can evaluate important intellectual skills. Nevertheless, while the coursework essay evaluates integrated knowledge and understanding, it often fails to facilitate reflective learning. By testing knowledge instead of ability, it frequently results in mere surface learning. In addition, the coursework essay tends to reflect what students perceive to be expected of them (the "rules"), without applying this to their own personal experience; and where knowledge is applied, it is mostly done in an incoherent and poorly constructed fashion. The essay presents learning as an authoritative product instead of a gradual process during which learning is assimilated through reading, discussion and personal reflection. ${ }^{49}$

42 Nisbet in Dochy and McDowell 1997 Studies in Educational Evaluation 5.

43 Simonson, Smaldino, Albright and Zvacek "Assessment for Distance Education" in Dikli 2003 Turkish Online Journal of Educational Technology 14.

44 Dikli 2003 Turkish Online Journal of Educational Technology 14.

45 Ovens "Using the Patchwork Text to Develop a Critical Understanding of Science" 200340 Innovations in Education and Teaching International 133133.

46 Dikli 2003 Turkish Online Journal of Educational Technology 15.

47 Winkler in Dikli 2003 Turkish Online Journal of Educational Technology 14.

48 Winter 2003 Innovations in Education and Teaching International 116-117.

49 lbid. 
As such, the most effective way to use a coursework essay is in conjunction with other forms of assessment that do require critical reflection. $^{50}$ This, unfortunately, is impractical due to time-consuming marking processes and the possibility of subjective marking. ${ }^{51}$ So, although the coursework essay has the potential to test various important skills, it rarely does, with "cutting and pasting" of assignments and information sourced from the Internet a frequent occurrence.

A portfolio, in turn, is a typical example of an evidence-based learning assessment tool, being a collection of papers and other forms of evidence that show that learning has taken place. ${ }^{52}$ It is also defined as a purposeful collection of student work that exhibits students' efforts, progress and achievements in one or more areas. Representing a reflective, developmental process of learning by encouraging self-awareness in students, the portfolio must present evidence of self-reflection to serve its purpose. ${ }^{53}$ When using the portfolio as an alternative assessment tool, selectivity is key, as it can easily become too bulky and fail to demonstrate clearly that students have grasped the overall course structure. Other drawbacks include its impracticality for external examination and moderation purposes, and the need for careful planning to avoid "gaps" in assessment. ${ }^{54}$

Even though both the coursework essay and portfolio offer an opportunity for feedback from the lecturer, which is a key feature of alternative, authentic assessment, they leave little room for critical self-reflection by the student. ${ }^{55}$ In all disciplines, and in law in particular, self-reflection is crucial to gaining deeper insight into the field of study. For this reason, the authors opted to implement the PWT as alternative assessment tool in two LLM modules taught at the UFS, to see whether this method would test the skills that students are required to master.

\section{THE PATCHWORK TEXT (PWT) AS AN ALTERNATIVE ASSESSMENT TOOL}

The PWT is a series of short, challenging tasks ("patches") prepared in the course of a module. Individual preparation of these patches is usually followed by group sharing to allow for not only self-evaluation, but also evaluation by peers. The student normally selects the "best" task to include in a final portfolio, complemented by short student reflections on the different tasks and their own learning. This is characterised by a final, short overview, in which all the learning patches are "stitched" together to show that the student has gained a macro-vision of the module. ${ }^{56}$

50 Winter 2003 Innovations in Education and Teaching International 117.

51 Simonson et al in Dikli 2003 Turkish Online Journal of Educational Technology 14.

52 Davis, Friedman, Harden, Howie, Ker, McGhee, Pippard and Snadden "Portfolio Assessment in Medical Students' Final Examinations" 200123 Medical Teacher 357357.

53 Dikli 2003 Turkish Online Journal of Educational Technology 14.

54 Winter 2003 Innovations in Education and Teaching International 9.

55 Surridge, Jenkins, Mabbett, Warring and Gwynn "Patchwork Text: A Praxis Oriented Means of Assessment in District Nurse Education" 201010 Nurse Education in Practice 128

56 Winter in Van Tonder et al 2005 SAJHE 1285. 
The PWT differs from the portfolio described in the previous section, in that it is an abridged version of a portfolio. In the PWT, the student chooses from a varied selection of short assignments and creates a coherent end product. The PWT should not be merely a collection of items, which the portfolio sometimes is, but should tell a well-structured story of learning, in which the students themselves interpret course material and select key tasks. These tasks should pertain to different skills, from academic writing to experiential accounts, allowing students to draw on their strengths as well as improve on their weaknesses. The central part played by the student in this assessment method makes PWT the ultimate learner-centred assessment tool.

According to Trevelyan and Wilson, ${ }^{57}$ the objectives of the PWT are continuous learning, deep learning, integrated understanding and critical self-reflection. These also happen to be the desired graduate attributes suggested by the Council on Higher Education (CHE). ${ }^{58}$ Moreover, the PWT is reliable, valid and credible, which is in line with SAQA's stated principles for assessment. ${ }^{59}$ This alignment with these key guiding documents in the South African higher education sphere confirms that the PWT can be a valuable tool to deliver students with the right skills to meet the demands of the workplace.

Requiring students to gain new knowledge or perspectives, and critically reflect on work previously done, the PWT promotes active learning. Active learning engages students in an activity that forces them to think about and comment on the information presented. ${ }^{60}$ Moreover, it assists students to analyse, synthesise and evaluate information in discussion with peers by asking questions, or through writing ${ }^{61}$ All of this challenges them to higherorder thinking. Social feedback from peers is equally critical. ${ }^{62}$ This entails comments from peers and teachers because one advantage of formative assessment is that the emphasis is on learning as a process rather than a measurement exercise. This is normally achieved when students present their tasks in a workshop fashion at prearranged contact sessions, where open discussions take place. The aim is to improve the presented task through self-assessment as well as assessment by peers and the facilitator.

As mentioned earlier, the final task of the PWT should be a "stitching together of the different patches" to make up a comprehensible, coherent whole in the form of a retrospective commentary resembling a reflective journal. Far from being random pieces of writing, the value of this final task lies in its organic nature ${ }^{63}$ as students systematically produce a personal reflection on their learning progression in the module. ${ }^{64}$ This is critical to the

\footnotetext{
Trevelyan and Wilson 2012 Assessment and Evaluation in Higher Education 487.

CHE Qualification Standard for Bachelor of Laws (LLB).

SAQA Criteria and Guidelines for Assessment of NQF Registered Unit Standards and Qualifications 43.

60 Stanford University "Active Learning: Getting Students to Work and Think in the Classroom" 19935 Stanford University Newsletter on Teaching 11

61 Ibid.

62 Upton and Taylor 2013 Psychology Teaching Review 45.

63 Richardson and Healy "Beneath the Patchwork Quilt: Unravelling Assessment" 201338 Assessment and Evaluation in Higher Education 847848.

64 Upton and Taylor 2013 Psychology Teaching Review 45.
} 
success of the PWT. Students tend to study in compartments and lose sight of the bigger picture. This final task forces them to develop a macro-vision, and shows whether they have reflected and gained deeper insight as opposed to mere rote learning. ${ }^{65}$ This reflection fosters the deep learning so sought after in higher education, and can be further enhanced by appropriate lecturer feedback. Self-reflection also helps with lifelong learning, as it teaches students how to identify gaps in their own work that need to be filled. In summary, therefore, the PWT enables gradual learning that is facilitated by ongoing feedback and evaluation through critical reflection and peer evaluation. ${ }^{6}$

In light of the above, replacing the traditional essays and written examinations of a structured master's programme with the PWT should prove valuable. While various research skills are already assessed in the master's programme, certain gaps persist; the PWT may bridge or narrow these gaps. For instance, when asking students to write essays, only a certain section or topic of the work is covered; with the PWT, a variety of topics is addressed.

\section{GUIDELINES FOR DRAFTING THE PWT ASSESSMENT}

The flexibility of the PWT, lending itself to be adapted to suit virtually any module, is one of its greatest strengths. ${ }^{67}$ But, although highly flexible, the PWT assessment requires the presence of certain core elements in order to be defined as such. It must comprise multiple assessment tasks, which must be properly paced and, eventually, form an integrated, comprehensive whole. $^{68}$ Before reporting on the findings of the implementation of the PWT in postgraduate law modules at the UFS, this section therefore provides a few broad guidelines to be considered in drafting and implementing this type of assessment.

First, both lecturers and students need to be clear as to the benefits associated with the implementation of the PWT. Learners must be thoroughly informed of what is expected of them in completing the PWT; the process must be clearly understood, practically executable, and properly regulated by the responsible lecturer. ${ }^{69}$ This also contributes to the transparency of the assessment. The various short tasks should be carefully planned and documented beforehand, with clear instructions. ${ }^{70}$

Secondly, the PWT must allow for self-assessment as well as assessment by peers and facilitators throughout, based on pre-formulated, properly communicated criteria. Self-reflection can help students plan their work, monitor their own progress, and evaluate and value their own

\footnotetext{
Winter 2003 Innovations in Education and Teaching International 118-120.

Wesson 2013 Psychology Teaching Review 98.

Trevelyan and Wilson 2012 Assessment and Evaluation in Higher Education 388.

Trevelyan and Wilson 2012 Assessment and Evaluation in Higher Education 494.

Joubert 2013 Journal of College Teaching and Learning 56.

Van Tonder et al 2005 SAJHE 1303.
} 
accomplishments. ${ }^{71}$ Learners should be carefully guided to master the art of critical self-reflection, which can be done as part of a short assignment. The connection between the short assignments and the macro-vision of the module must be emphasised. In addition to self-reflection, discussion with peers is important, as different perspectives can be appreciated, while lecturers should also provide constructive feedback.

Thirdly, careful consideration is required when selecting the appropriate tasks to test the desired skills and learning outcomes. Different skills can be tested by different tasks. Proper task selection could also enhance previously underdeveloped skills, which may become valuable assets to the student. Ultimately, the selected tasks should give students an overall view of the subject and force them constantly to work and review what they have done. One way of achieving this is to allow students to write various short pieces of text at a time (perhaps on a weekly basis), which they can then join together to create a framework for a final written assessment.

The only area in which this form of assessment may be faulted is its impracticality in large classes. Wesson agrees, ${ }^{73}$ stating that the PWT assessment is "suited to small, motivated and coherent groups of students where the workload of both the staff and students can be more easily managed". For this reason, implementing the PWT in undergraduate modules might prove more challenging. However, applying it in postgraduate modules, where student numbers are usually low, makes perfect sense.

To draft this form of assessment and update it every year could be challenging and time-consuming, but is worth the effort. It not only reassures the lecturer that students' broader knowledge of the law, as demanded by the profession, is being tested more credibly than by any other form of assessment, but also benefits the student by developing vital legal writing and communication skills.

\section{IMPLEMENTING THE PWT FOR POSTGRADUATE TEACHING}

The authors were both personally introduced to the PWT as part of the Master of Arts in Higher Education Studies (MA HES) programme at the UFS, where this assessment technique was implemented by Van Tonder and colleagues. ${ }^{74}$ Despite challenges with arranging meetings for group work and ensuring all group members' participation, the authors' experience of participating in group work, obtaining a macro-vision and building "teamship" was largely positive.

Joubert 2013 Journal of College Teaching and Learning 58.

Richardson and Healy 2013 Assessment and Evaluation in Higher Education 848.

Wesson 2013 Psychology Teaching Review 104.

74 Van Tonder et al 2005 SAJHE 1302-1303. 


\section{Practical application in other postgraduate modules}

The PWT assessment tool was used to good effect in higher-learning programmes in health and social care in the United Kingdom. ${ }^{75}$ Students experienced it very positively, although one indicated that some group members frequently made excuses for not completing the work, which was to the detriment of others as complete idea-sharing could not take place. The student found it very frustrating that some group members gave more, while others ended up taking more ${ }^{76}$ As mentioned above, this was the authors' own experience as well.

To resolve this problem, it is suggested that proper peer evaluation be done frequently and honestly, so that group members can relay and report on the actual group dynamics. Although frustrating, it is unfortunately a fact of life that some people do more, and others get away with doing less. The PWT forces students into a situation where they need to learn to cope with this reality, a valuable skill in itself. In addition, students usually benefit from sharing their work, as it gives them greater insight into the subject and opens their minds to views other than their own. Students in the health and social care programmes mentioned above echoed these sentiments and indicated that they had gained deeper insight into other people's roles and professions. One student indicated that the PWT had stimulated him to further analyse his ideas, which resulted in an increased sense of selfawareness. ${ }^{7}$ These are all desired teaching-and-learning outcomes in any discipline taught at a higher level.

The PWT was successfully introduced in a Master of Arts in Business Management group, also in the United Kingdom. ${ }^{78}$ Here too, the lecturer experienced the same challenge with group work but noticed a changing dynamic between the students. Soon, those who did not commit fully started to feel the pressure due to group norms, resulting in an emerging sense of group responsibility. The lecturer observed a natural form of coaching between students, with the stronger students helping the weaker ones. ${ }^{\text {.9 }}$ She acknowledged the challenges of the PWT, but found that the benefits outweighed the difficulties, and that students developed a more in-depth understanding of the module. ${ }^{80}$

75 Crow, Smith and Jones "Using the Patchwork Text as a Vehicle for Promoting Interprofessional Health and Social Care Collaboration in Higher Education" 20054 Learning in Health and Social Care 117 117-128.

76 Crow et al 2005 Learning in Health and Social Care 122.

77 Crow et al 2005 Learning in Health and Social Care 123.

78 Illes "The Patchwork Text and Business Education: Rethinking the Importance of Personal Reflection and Co-operative Cultures" 200340 Innovations in Education and Teaching International 209209

79 Illes 2003 Innovations in Education and Teaching International 211.

80 Illes 2003 Innovations in Education and Teaching International 212. 


\section{Practical application in the Advanced Property Law module of the structured Master of Law programme at the UFS}

The authors of this article have implemented the PWT in two modules namely, Advanced Property Law, and International Free Trade and Free Trade Agreements. Both form part of the structured Master of Law programme at the UFS. For the purposes of this article, discussion is limited to the introduction of the PWT in Advanced Property Law.

The lecturer presents the module in a resource-based mode, with the underlying assumption that candidates will learn through direct confrontation with learning resources, as well as activities linked to those resources, instead of through a conventional exposition of content. Therefore, students are expected to take greater responsibility themselves. ${ }^{81}$ Self-study is expected, and thorough preparation for formative assessment exercises is a prerequisite. Attendance of workshops is compulsory.

Formative assessment exercises are designed to enhance the students' knowledge of and insight into the topic. Students must each prepare their assignments for the workshops in advance. These formative exercises then constitute the basis of workshop discussions. During the workshops, the exercises are assessed and improvements suggested through peer and facilitator input. The final exercises are compiled in a portfolio of evidence of learning, on the basis of which the summative assessment is conducted and a semester mark is obtained.

Examples of the formative assessment exercises introduced include the following:

a) writing a book review in which students have to compare the property clause in the South African Constitution to the property clause in the constitutions of two other countries of their choice;

b) preparing a PowerPoint presentation (with notes included), explaining the difference between expropriation and deprivation, introducing the proposed new Expropriation Bill, and indicating the changes that will affect the current position;

c) designing a Venn diagram or mind map on differences in the application and procedure of land-reform legislation;

d) preparing a short newspaper article in which students inform the community on a certain property-law issue identified by the lecturer;

e) writing a formal letter to the editor of a newspaper explaining misconceptions regarding the owner's right to evict illegal occupants from his property;

f) drafting a table to indicate different legislation promulgated in the land reform space;

81 UFS “UFS Form 5: Short Learning Programme" (2005) https://apps.ufs.ac.za/dl/slp/91 Assessment\%20 of\%20learning\%20in\%20Higher\%20Education\%20UFS\%20FORM\%205.p df (accessed 2011-03-12). 
g) participating in a mock radio interview as part of a fictitious programme called "What Does the Law Say?" with "listeners" (peers) phoning in with problems that need to be solved;

h) presenting students with a set of facts on which they are expected to provide legal advice to a client;

i) conducting an interview to determine a peer's perspective on the "public trust" doctrine currently applicable in South Africa's water law, and then preparing a write-up of the interview; and

j) conducting a debate with peers to ascertain different cultural perspectives on the relationship between private law rights and socioeconomic rights as influenced by the new water legislation dispensation, with students being expected to write their own critical reflection on the various perspectives following the debate, as well as record their own learning experiences throughout the exercise.

As these exercises require a vast amount of reading and reflection involving higher-order thinking skills, tasks need to be carefully selected to ensure that all learning outcomes are covered - not only in terms of module content, but also the range of skills that students are expected to acquire during the module. The ultimate selection of tasks to be included in the PWT depends on the lecturer, who should decide which exercises are more suitable for the particular module. The exercises selected should stimulate students to reflect critically on the value of their learning, and should encourage a deeper sense of understanding of the module content and the relevance of knowledge. Furthermore, it should promote the use of technology and enhance learners' technological skills, which are crucial in this digital age. Students should also be urged to research their own reference material, and must receive credit for doing so.

In order to obtain a year mark (predicate) that contributes 20 per cent towards the final mark, the formative assessments are submitted in the format of a portfolio. This portfolio of evidence of learning is handed in together with the PWT assessment. However, the PWT forms the basis of the summative assessment (examination). Thus, the PWT itself serves as the summative assessment tool. Initially, students completed a set, openbook examination at a computer laboratory that had word-processing features, but no internet or other type of collaborative access. However, as the module developed, it became clear that the time constraints and set examination venue negatively affected students' creative and reflective output. At present, therefore, the paper is designed as a take-home, openbook examination on the full scope of work dealt with in the various units. As supported by external examiners' reports and personal experience, it is most likely that the students' success in the assessment is integrally linked to their ability to display a macro-vision of the subject, integrate and contextualise the different areas of property law, and reflect critically on new, emerging developments in the field.

As to the set-up of the examination paper, ${ }^{82}$ students are required to design a cover page for their PWT, indicating their details and the module

82 This was adapted from a study guide used in the MA HES course at the UFS, drafted by Dr Fanus van Tonder. 
code. The background of the cover page should include a collage to serve as a visual PWT of the main themes they have dealt with in the module. Students may make use of any media reports, pictures or other electronically available visual material to depict the theme of their study. They then have to compile a complete table of contents for the PWT and portfolio, clearly indicating the page numbers of all assignments and appendices. Next, students are given four tasks that will make up the "patches" of the PWT. The purpose of the first three patches is to afford them an opportunity to look back and reflect critically on the three themes explored during the semester. Task four is a reflective commentary on the module as a whole, in which students have to "stitch together" the different patches of their learning and development.

Tasks one, two and three are essentially the same. These patches require students to reflect critically on their experiences relating to each unit, indicating the possible value of their experiences, what they have learnt, and how they can apply (or have applied) their newly acquired knowledge in the field of property law or any other discipline. They could also suggest how the theme as a whole may be improved or adapted. In task four, students then indicate how all the assignments relate to one another, and how each learning experience (both individually and cumulatively) contributed to the attainment of the critical and specific learning outcomes of the module. With this final task, students need to display a macro-vision of the latest developments in the field of property law as well as in their personal development.

\section{CONCLUSION}

The authors' experience is that the PWT has forced students to engage deeply with the study material. It fosters deep learning and enables students to focus on the module as a whole rather than only on those parts relevant to assignments. The formative tasks not only develop various generic skills, including group work, use of technology, and legal writing, but also ensure critical reflection on the learning material. The critical self-reflection fostered by the PWT helps motivate students to achieve even more and monitor their own progress. As such, it empowers students to take control of their own learning and gain deeper insight into the discipline of law. The peer evaluation component, in turn, contributes to the transparency of the assessment tool and ensures participation throughout the module. Finally, the ultimate "stitching together" of the patches ensures the development of a macro-vision of the field of study.

Feedback from both the external moderators and students has been very positive, and their recommendations will be included in the future development of the assessment tool. One external moderator gave the following feedback:

"This is an excellent and innovative module. As one of the students stated him- or herself, it does not simply require the students to "cram". Instead, it requires students to analyse, debate and critically reflect on the material they have covered in a structured manner. It is quite clear to me that the lecturer has given careful thought to the manner in which the module should be structured, taught and assessed. I am not aware of any other postgraduate 
law module which uses the patchwork approach. This is unfortunate because it seems to me that this is particularly suitable for postgraduate studies."

In their feedback, the students commented mainly on the skills they had acquired, such as critical, analytical and comparative skills. They seemed to have experienced the module as a fresh approach compared to traditional assessment. Students also indicated that the way in which the paper was set forced them to gain insight into, and develop a macro-vision of, property law in general.

Overall, the PWT has proved to be a viable tool for assessing postgraduate students in the selected law modules at the UFS, and could even be employed at undergraduate level where class sizes permit. It promotes deep learning, critical thinking and problem-solving, and forces students to engage continuously with the study material. In addition, the PWT achieved the intended learning outcomes of the modules. Thus, it is envisaged that the PWT will continue to be used going forward. 